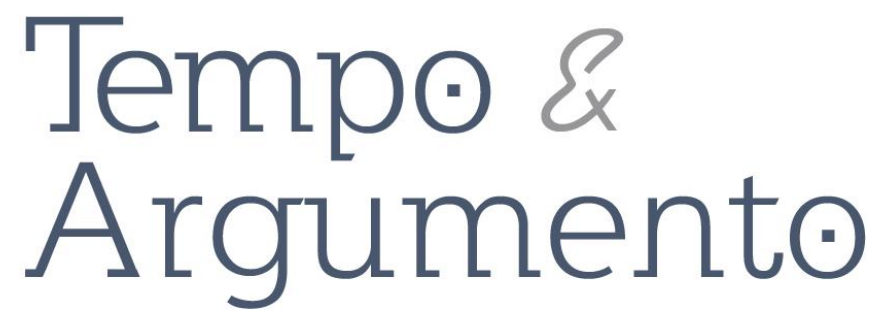

\title{
A educação na sociedade rural e o curso agrícola para rapazes brasileiros na Polônia (1918 - 1938)
}

\begin{abstract}
Resumo
O artigo trata da educação de jovens brasileiros, filhos de imigrantes, na Polônia, entre os anos de 1937 e 1938. O estudo parte dos antecedentes de pesquisas realizadas em torno da educação rural no Brasil, iniciadas por volta de 1917/1918, pelo pensamento de um dos intelectuais da educação deste período, Antônio Carneiro Leão. O objetivo consiste em analisar as relações entre Brasil e Polônia no que tange à educação dos imigrantes trabalhadores rurais, especialmente no período mencionado. $O$ corpus documental se constituirá de jornais e documentos oficiais, encontrados na Biblioteca da Universidade de Cracóvia e no Arquivo de Atas Novas em Varsóvia. Por fim, o resultado mostra que as proposições apresentadas inicialmente por Carneiro Leão sobre a educação na sociedade rural são correligionárias com o que encontramos nas fontes documentais que dialogam entre os dois países no período evidenciado e que, portanto, sinalizam uma vocação agrícola para o Brasil.
\end{abstract}

Palavras-chave: Educação rural. Poloneses. Brasil. História.

\author{
Alcione Nawroski \\ Doutora em Educação pela Universidade \\ Federal de Santa Catarina (UFSC). \\ Professora da Universidade Federal de \\ Santa Catarina (UFSC). Atualmente realiza \\ estágio pós-doutoral na Universidade de \\ Varsóvia/Polônia pelo Programa de Pós- \\ doutorado no exterior/Capes/Brasil. \\ Varsóvia - POLÔNIA \\ alcione.nawroski@gmail.com \\ orcid.org/0000-0002-9036-7169
}

\section{Para citar este artigo:}

NAWROSKI, Alcione. A educação na sociedade rural e o curso agrícola para rapazes brasileiros na Polônia (1918 - 1938). Tempo e Argumento, Florianópolis, v. 11, n. 28, p. 67 97, set./dez. 2019. 


\section{Education in rural society and the agricultura course for Brazilian boys in Poland $(1918-1938)$}

\begin{abstract}
The article deals with the education of young Brazilians, children of immigrants, in Poland between 1937 and 1938. The study is based on the antecedents of research on rural education in Brazil, started around $1917 / 1918$ by the thought of one of the education intellectuals of this period - Antônio Carneiro Leão. The objective is to analyse the relations between Brazil and Poland concerning the education of immigrant rural workers, especially in the defined period. The documentary corpus will consist of journals and official documents found at the University of Krakow Library and the Archive of Modern Records in Warsaw. Finally, the result shows that the proposals originally submitted by Carneiro Leão on education in rural society are similar with that to be found in documentary sources that dialogue between the two countries on the emphasized period, and therefore signal an agricultural vocation for Brazil.
\end{abstract}

Keywords: Rural education; Polish; Brazil; History.

\section{La educación en la sociedad rural y el curso agrícola para rapazes brasileños en Polonia $(1918-1938)$}

\begin{abstract}
Resumen
El artículo trata sobre educación de jóvenes brasileños, hijos de inmigrantes, en Polonia, entre los años de 1937 y 1938. El estudio se basa en los antecedentes de la investigación sobre educación rural en Brasil, iniciada alrededor de 1917/1918, por el pensamiento de uno de los educadores y intelectuales de este período - Antônio Carneiro Leão. El objetivo es analizar las relaciones entre Brasil y Polonia a cerca de la educación de los trabajadores rurales inmigrantes, especialmente en el período mencionado. El corpus documental consistirá en revistas y documentos oficiales encontrados en la Biblioteca de la Universidad de Cracovia y en el Archivo de Registros Modernos en Varsovia. Al final, el resultado muestra que las propuestas presentadas originalmente por Carneiro Leão sobre educación en la sociedad rural son similares a las que se encuentran en las fuentes documentales que dialogan entre los dos países en el período enfatizado y por lo tanto señalan una vocación agrícola para Brasil.
\end{abstract}

Palabras clave: Educación rural; Polacos; Brasil; Historia.

\section{Introdução}

O artigo resulta dos antecedentes de pesquisa sobre Antônio Carneiro Leão (1887-1966), o qual proferiu inúmeras vezes que o Brasil é um país essencialmente agrícola e, portanto, deve-se cultivar a terra com amor. Sendo assim, o educador brasileiro dedicou-se a uma série de estratégias pedagógicas para, tomando emprestado o termo de John Dewey, promover um bring up ${ }^{1}$ pela terra, entre os colonos imigrantes

\footnotetext{
1 Para Dewey (1916), ao ingressar na escola, a criança traz uma carga de conhecimentos e imitações comportamentais já transmitidas pelos adultos. Cabe, portanto, à escola tomar o contato com a realidade da criança para selecionar as experiências fundamentais ao progresso da sociedade e realizar um bring up, isto é, aflorar suas emoções e sentimentos sem perder de vista a direção, o controle e a orientação.
} 
que chegavam ao Brasil no período que antecedia o início da II Guerra. Destarte, apostar na expansão de escolas rurais durante as décadas de 1920 e 1930, foi uma estratégia bastante promissora, não só no Brasil, mas também em outros países da América Latina como Argentina, Chile e México.

Quanto à construção de mais escolas rurais para os imigrantes, o educador criou estratégias curriculares e pedagógicas como a formação específica de professores para o campo, cuja carga horária era reduzida se comparada ao demais cursos de formação de professores, com conteúdo específico para atuarem nas escolas que mais se afastavam dos centros urbanos. Em relação à imigração, Carneiro Leão fez algumas observações e destacou que no estado de São Paulo não parece haver problemas com os imigrantes italianos que chegam ao Brasil, porque eles se adaptam facilmente à língua portuguesa e não representam perigo à harmonia nacional. Já em relação aos alemães do sul, não arrisca dizer o mesmo, pois segundo o educador, lá ecoa um brado jacobino: “Allemanismo no Brasil” (CARNEIRO LEÃO, 1918, p. 130), um eco que também respinga nos imigrantes poloneses, tendo em vista que a maioria deles chega à custa dos navios alemães falando uma língua bastante distinta do português.

O educador brasileiro ainda usou o exemplo da Polônia, ao citar que a língua mãe pode representar um grande problema ao Brasil porque mantém a sensibilidade, a cultura e a galhardia da nacionalidade de origem. Por fim, mencionou o que se passou na Polônia até o final da I Guerra, especialmente nas regiões que estavam sob o domínio Prussiano e Russo, cujos habitantes vinham sendo impedidos de falar a língua materna nos espaços públicos, tendo que substituí-la pelo alemão ou russo, respectivamente, como uma imposição do Reino da Prússia e do Império Russo.

Carneiro Leão (1918) entendia que o apodrecimento da língua também mata as tradições e as venerações históricas do seu país. O educador acreditava que a melhor forma de apagar a carga histórica que os colonos imigrantes traziam por meio da sua língua mater e da sua nacionalidade era divulgar e ensinar "nossa história, fazendo-a amante dos nossos fatos, carinhosa pela nossa terra, associando-a ao progresso da civilização brasileira" (CARNEIRO LEÃO, 1918, p. 130). Assim, a ideia do amor pela terra 
como uma estratégia pedagógica apareceu desde as primeiras publicações, entre elas, “O Brazil e a educação popular" (1918):

Cultivar a terra é a necessidade primeira, uma educação que nos leve a fazê-lo, com amor e proveito, a mais sabia medida para o engrandecimento da pátria. E não só o tamanho da terra, mas a fomentação das indústrias, a competência, a capacidade para a ação e o trabalho produtor, são os meios únicos de fazerem do Brazil, fraco e pobre, uma nacionalidade respeitada e grande. (CARNEIRO LEÃO, 1918, p. 35)

Uma educação rural que despertasse um conjecturado sentimento de "amor à terra" foi uma tese defendida pelo educador apresentada em várias de suas publicações e aqui, destacamos especialmente aquela publicada no final dos anos de 1930, "A sociedade rural - seus problemas e sua educação" (1939). Diante da questão levantada, o intelectual elaborou um arcabouço teórico-metodológico por meio da sociologia e psicologia experimental cujo objetivo era formar professores para atuarem nas escolas rurais no Brasil. Não pretendemos tratar aqui da formação de professores, tampouco dos materiais que o educador elaborou para a educação rural, mas elucidar algumas de suas ideias para contextualizar a sociedade rural entre os anos 1918-1938, de maneira especial no contexto que concerne à imigração polonesa. Ademais, compete aqui, lançar algumas notas sobre os poloneses no Brasil, também compreendida pela maioria dos historiadores poloneses como uma "febre brasileira" dividida em três momentos distintos, entre os anos de 1869 e 1939 .

Com o arrefecimento do escravismo no Brasil, uma nova oportunidade se abriu inicialmente aos jovens rapazes das regiões da Prússia e da Galícia. Eram jovens que, sedentos por uma oportunidade de trabalho, se jogavam por conta própria, sem nenhuma assistência do Governo, nos navios alemães ou italianos, em míseras condições, passando fome e sede até alçarem a terra prometida.

Os ecos de prosperidade dessa terra que chegavam dos agentes de imigração da Alemanha e Itália, ecoavam especialmente nos ouvidos dos rapazes camponeses pobres e pequenos artesãos. Mas a notícia, disseminada facilmente pelas escolas e igrejas, se espalhava rapidamente por todas as regiões do território de língua polonesa despertando 
interesse também nas famílias dos empregados das fábricas e do campo, além dos pequenos camponeses. Dessa forma, o processo das ondas imigratórias se iniciava, primeiramente entre rapazes trabalhadores e em seguida, famílias inteiras rapidamente se desfaziam de todos seus bens materiais para apostar na terra prometida, conhecida metaforicamente como a terra onde as árvores produzem leite e mel.

Para Mazurek, existia uma diferença entre os emigrantes que embarcavam para a América do Sul daqueles que partiam para a América do Norte:

O que diferenciava a imigração das terras polonesas ao Brasil, e em parte também a Argentina, da imigração aos Estados Unidos, era o fato de que para a América do Sul, a maioria viajava com as famílias inteiras. O objetivo da viagem era a conquista de uma propriedade particular que garantisse uma vida segura. [...] No caso da América Latina, [...] a colonização rural apresentava outras exigências. Ali, sem a presença da família, pelo menos da esposa, estabelecer-se na propriedade seria quase impossível. (MAZUREK, 2016, p. 55)

Dadas as condições brasileiras, cada vez mais, o país passou a ser destino de famílias jovens com filhos pequenos que acreditavam na promessa anunciada pelos agentes da imigração alemã como uma terra de leite e mel. Mesmo que o processo de imigração tenha sido contínuo, os maiores picos ou ondas de imigração durante o período da "febre brasileira" foram marcados por três momentos distintos quando chegaram ao Brasil nos anos de: 1) 1890-1891 - aproximadamente 65 milhões de imigrantes; 2) 18951896 - aproximadamente 25 milhões de imigrantes; e 3) 1911-1912 - aproximadamente 10 milhões de imigrantes.

Apresentamos abaixo, um mapa encontrado no Arquivo de Atas Novas de Varsóvia, o qual ilustra as principais colônias de imigrantes até o ano de 1899, contemplando os dados da primeira e segunda onda da "febre brasileira". Contudo, esses dados são importantes porque demarcam as principais regiões de instalação dos imigrantes poloneses no Brasil, tendo em vista que foram regiões demarcadas pela etnia e adensadas pelos colonos imigrantes que chegavam com o passar dos anos. 
Figura 1 - Colônias de camponeses poloneses nos três estados do Sul do Brasil

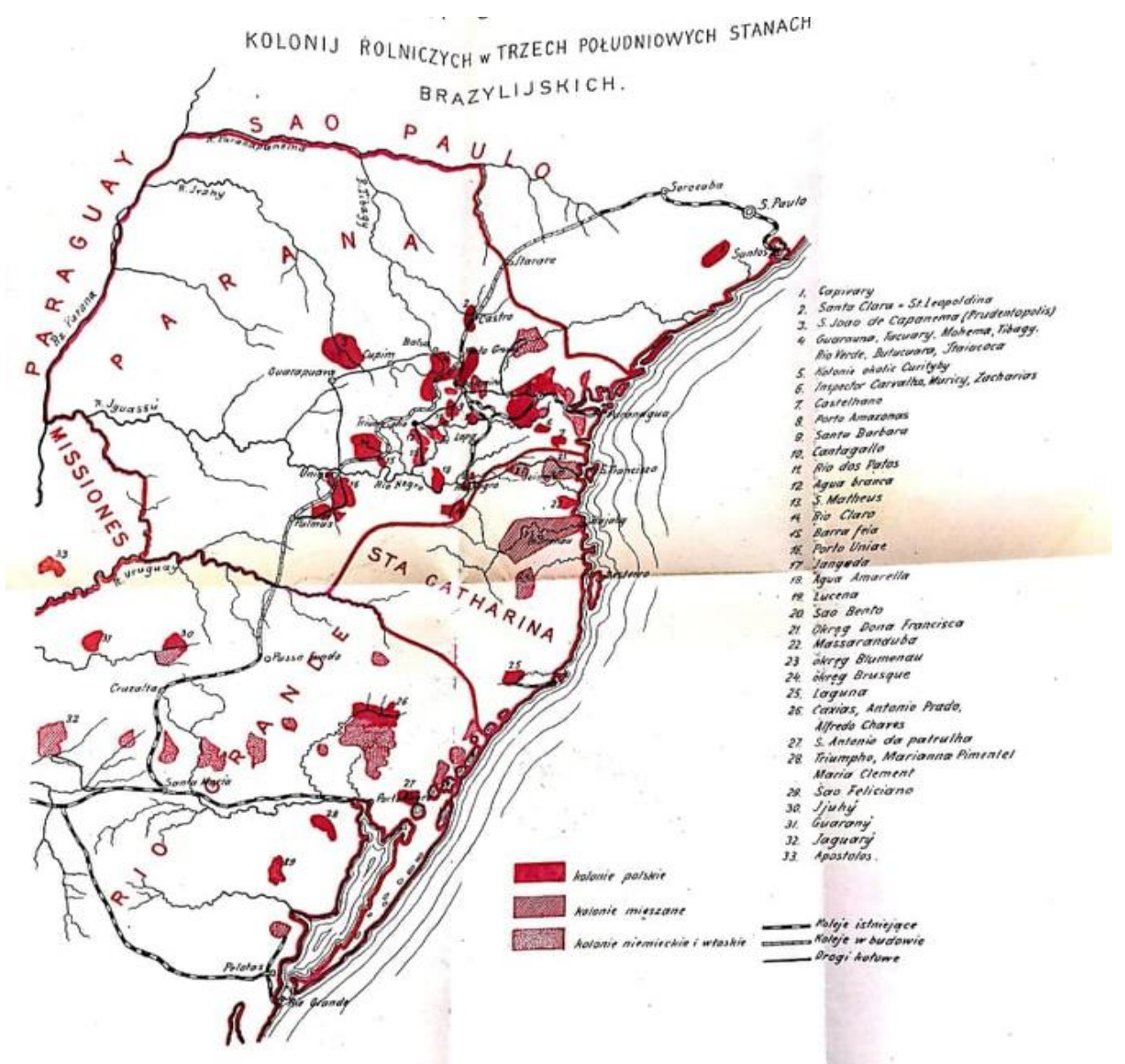

Fonte: BRAZYLIA. Dekrety i rozporządzenia imigracyjne. Archiwum Akt Nowych: Warszawa.1899.

Passados os duros anos da I Guerra Mundial, o Tratado de Versalhes e, por fim, a recontextualização do Estado polonês, diferentes medidas foram tomadas como forma de auxiliar os imigrantes poloneses em outros países. Muitas dessas medidas puderam ser acompanhadas pelo jornal Polacy Zagranica que apresentava informações e dados sobre a diáspora polonesa pelo mundo e onde também encontramos o relato dos jovens que participaram de um curso agrícola na Polônia.

A partir das ideias de Carneiro Leão, ilustramos o cenário da imigração polonesa na sociedade rural brasileira, bem como o movimento de uma educação apropriada a esses imigrantes que chegavam sedentos por terra. Por outro lado, apresentamos alguns dados da Polônia que após o restabelecimento do Estado, em 1918, buscou se aproximar dos seus emigrados no Brasil por meio de algumas concessões como a organização de 
diversas associações e a oferta de bolsas de estudo, destinadas a filhos de imigrantes poloneses na Escola Agrícola de Blichu. Além disso, também tratamos da edição dos jornais que buscavam intercambiar e aproximar os dois países naquilo que os unia, ou seja, a vida e a promoção cultural dos colonos imigrantes. Em seguida, apresentaremos o processo de recrutamento e a participação dos estudantes no curso bem como as relações entre Brasil e Polônia, notadamente nos anos de 1937 e 1938, quando os estudantes realizam o curso evidenciado.

A pesquisa foi realizada por meio de um corpus documental composto por jornais catalogados na Biblioteka Jagiellońska, da Universidade Jaguelônica, de Cracóvia, e documentos encontrados no arquivo AAN - Archiwum Akt Nowych ${ }^{2}$ de Varsóvia, na pasta Kursy Rolnicze - Brazylia (Cursos Agrícolas - Brasil). À luz das ideias de Carneiro Leão, o trabalho dar-se-á pela análise dos documentos supracitados que tratam da realidade social brasileira, especialmente no que se refere à educação dos trabalhadores descendentes de imigrantes, bem como pela apresentação das relações por meio de ofícios trocados entre os dois países, no período em que jovens rapazes brasileiros se deslocaram para realizar seus estudos. Além dos documentos, escolhemos as reportagens que tratam do Brasil, publicadas pelo Jornal Polacy Zagranicą ${ }^{3}$, entre os anos de 1930 e 1938, com o propósito de relacionar a função social da escola agrícola com as determinantes sociais e econômicas desse período.

Diante da apresentação desta pesquisa, demarcamos por meio de Carr (1996), nosso tempo e lugar na realização deste trabalho. Para o historiador britânico, fazer história hoje é fazer história contemporânea, porque fazer história consiste basicamente em ver o passado pelos olhos do presente e à luz dos seus problemas, tendo em vista que o historiador pertence ao presente e não ao passado. Partindo dessa premissa, adotamos como metodologia, alguns elementos versados durante a terceira geração dos Annales, quando "a história passa a ser influenciada pela 'antropologia simbólica' incrementada

\footnotetext{
${ }^{2}$ Arquivo de Atas Novas é um arquivo de registros modernos situado no Bairro Ochota, em Varsóvia/PL.

3 Jornal mensal "Poloneses no Estrangeiro" foi editado em Varsóvia/PL, entre os anos 1930-1939 e tratava das questões sociais, culturais e econômicas dos emigrados. $O$ jornal mantinha publicações mensais até o início da II Guerra Mundial, em setembro de 1939. Desde 1935, era considerado um jornal mundial porque seus exemplares passaram a ser encaminhados para diversos países, cujo número de leitores da língua polonesa fosse expressivo (POLACY ZAGRANICA, 1938).
} 
pelos estudos de Erving Goffman e Victor Turner que tratam dos aspectos cotidianos". Outros nomes também aparecem como os estudos de Pierre Bourdieu, Michel de Certeau e Roger Chartier (NAWROSKI, 2015, p. 65).

Em relação à leitura e análise dos textos escritos nos jornais e livros, Chartier (1998) destaca que os leitores são de carne e osso cujas maneiras de interpretar variam de acordo com as épocas, lugares e ambientes. Por último, acrescentaríamos ainda os desafios da leitura e interpretação de jornais escritos na década de 1930, num país cuja língua oficial é o polonês. Assim, gostaríamos de marcar nosso olhar de pesquisador enquanto leitores de carne e osso, determinados por um tempo e espaço. Por fim, sublinhamos que o trabalho é fruto da conclusão de uma tese de doutorado que aponta a projeção de uma vocação agrícola para o Brasil, explicitada durante a primeira metade do século XX, pelo pensamento de Antônio Carneiro Leão.

O trabalho versará inicialmente sobre a sociedade rural brasileira apresentada pelo jornal polonês Polacy Zagranica, um jornal fundado em 1930, que tratava da diáspora polonesa nos mais diversos países, especialmente aqueles que contavam com uma presença expressiva de imigrantes. Em seguida, apresentaremos sobre o recrutamento, a participação e o retorno dos rapazes brasileiros que participaram do intercâmbio no Colégio Agrícola de Blichu, na Polônia. Na terceira parte, realizaremos uma análise da sociedade rural brasileira entre os anos de 1918 e 1938, tendo como elemento principal a educação e o processo de nacionalização das escolas no Brasil. E por fim, evidenciaremos algumas considerações que possibilitem um aprofundamento da temática, bem como a soma às demais pesquisas que vêm sendo realizadas nos últimos anos.

\section{A sociedade rural no Brasil pelo jornal Polacy Zagranicą}

O jornal Polacy Zagranicą noticiou, em janeiro de 1930, a inauguração da Associação de agricultores poloneses com o apoio das Relações Internacionais Polonesas com vista a manter e ampliar os espaços de cultura da imigração no Brasil. Com sede em Curitiba, a associação vem para se somar a outras já existentes como a associação de professores e demais organizações poloninas existentes e mencionadas por Kula (1976). 
O jornal também acrescentou durante o primeiro número de sua publicação, em 1930, que a associação foi criada para que os imigrantes não se sentissem tão longe de casa. E, para complementar, destacou que essa medida, sob o incentivo do Governo polonês, deveria ocorrer em todos os países marcados pela diáspora polonesa. Dentre as principais premissas da Associação de agricultores, constava a melhoria de vida dos colonos e a organização de mais e novas escolas para os jovens, filhos dos imigrantes. Sobre o anseio por mais escolas, Piton destacou que:

O imigrante, ainda que analfabeto, especialmente aqueles que vieram da ocupação russa, compreendeu, desde o início, a necessidade de escolas, de sociedades, de livros e da imprensa. Ressentia-se, plenamente consciente, da miséria a que fora relegado pela ocupação, pela classe dominante e pela nobreza a quem servia em total dependência. (PITON, 1971, p. 80)

Para o autor, além da sede de terra para plantar, os imigrantes também tinham sede de escola, cultura e leitura, ou seja, tudo aquilo que foi lhes negado no seu país de origem. No mês de abril do mesmo ano, o jornal Polacy Zagranicą publicou uma nota com o nome das pessoas que foram nomeadas para compor a diretoria da Associação no Brasil4. A reportagem ainda destacou que a partir daquele momento haveria uma programação regular de viagens aproximando os dois países, algo que até então era bastante irregular e, por vezes, dificultava uma comunicação adequada entre os países. Na medida em que o Estado polonês se fortalecia, novos e diferentes acordos entre os dois países vinham se estabelecendo, possivelmente motivados pelo Governo polonês tendo em vista que o Brasil foi o primeiro país da América Latina a reconhecer a Polônia Unificada e Independente, em 17 de agosto de 1918, durante uma nota encaminhada pelo Ministro das Relações Exteriores do Brasil, Nilo Peçanha a Paul Claudel, Ministro Plenipotenciário da França no Rio de Janeiro. Como resultado dessas relações de proximidades estabelecidas, o Brasil, além do fluxo contínuo de imigrantes ${ }^{5}$, começou a

\footnotetext{
4 BRAZYLIA. Powstanie Centralnego Związku Polaków. Polacy Zagranica, Warszawa, Nr. 4, s. 116 - 117. IV.1930.

5 Para Dembicz e Smolana (1993, p. 22) apud Trindade (2016, p. 128), afirmam que entre 1918/20 e 1939, ocorre uma segunda etapa da emigração massiva, desenvolvendo-se um período de uma "emigração dirigida", patrocinada e inclusive organizada pelo Estado. Nesse contexto, começam a aportar, intelectuais, operários e imigrantes com qualificação profissional; além da contínua maioria de camponeses. O Estado Polonês começou a preocupar-se com a questão emigratória concentrando-se sobre a política oficial frente à Comunidade polonesa na América Latina.
} 
receber um grupo de pessoas formando uma intelligentsia polonina, como jornalistas, professores e diplomatas.

Anos mais tarde, em setembro de 1935, o jornal Polacy Zagranica publicou uma reportagem sobre a importância e o desenvolvimento que a imprensa escrita teve no Brasil nos últimos anos (ŻABKO-POTOPOWICZ, 1935). O autor da matéria apontou a expansão dos jornais e notícias como um dado positivo, mesmo que a imprensa no Brasil viesse vagarosamente se expandindo, quando comparada ao número de reportagens que chegavam dos Estados Unidos na redação em Varsóvia/PL. Enquanto fazíamos a leitura do jornal Polacy Zagranica publicado mensalmente, pudemos observar que o autor da reportagem tinha razão ao mencionar que essa ampliação e qualificação das matérias foi se expandindo, pois podemos constatar que a cada ano o espaço dado ao Brasil vinha tomando mais corpo e qualidade com ilustrações, fotos, trechos de poesias e dicas de leitura. Além de verificarmos o aumento gradativo no tamanho das reportagens, também identificamos a diversificação dos temas relacionados ao Brasil que ocupavam o jornal, possivelmente como resultados dessa cooperação na formação de um quadro de intelligentsia após a Independência da Polônia.

Por outro lado, mesmo com o esforço do Estado polonês, a mesma matéria do jornal publicada em setembro de 1935, destacou que o desenvolvimento da cultura polonesa no Brasil não ocorreu da mesma forma quando comparado aos imigrantes alemães ou italianos. Isso aconteceu porque havia uma desvantagem inicial em relação aos imigrantes poloneses, quando pejorativamente muitas vezes foram chamados de “polacos sem bandeira”, como resultado da inexistência do Estado polonês durante seus 123 anos. E como consequência desse Estado desaparecido, uma grande parcela da população não conseguiu passar pela escola das primeiras letras, especialmente os camponeses e, portanto, era uma população analfabeta, formada apenas pelos princípios culturais da Igreja Católica. A reportagem também trouxe alguns dados estatísticos para ilustrar o perfil dos imigrantes: 
Tabela 1: Imigrantes poloneses no Brasil. (Tradução nossa)

\begin{tabular}{|l|l|}
\hline Profissão & Porcentagem \\
\hline Agricultores & $95,0 \%$ \\
\hline Trabalhadores e Artesãos & $3,5 \%$ \\
\hline Comerciantes e Industriais & $1,0 \%$ \\
\hline Intelectuais & $0,5 \%$ \\
\hline
\end{tabular}

Fonte: ŻABKO. P. B; Rozwój i znaczenie pracy polskiej w Brazylji. Polacy Zagranica, Warszawa, Rok 6, n. 9, IX. 1935, s.11.

Em relação aos intelectuais, a maioria eram jornalistas, escritores, diplomatas, advogados e outros representantes do Governo polonês que normalmente permaneciam no país por um período curto, não necessariamente fixando residência. Podemos afirmar que o país não era destino fixo dos intelectuais poloneses, principalmente no período entreguerras. Por outro lado, estudos como de Trindade (2016, p. 128), afirmam que a partir do restabelecimento do Estado polonês e com contínuo fluxo de colonos imigrantes, foram "instauradas as instituições diplomáticas e enviados vários intelectuais poloneses com o fito de manter e divulgar a polonidade entre os emigrantes" no Brasil. Acreditamos que a afirmação de Trindade, ajuda a explicar o grupo de intellectus que repercutiu na expansão da imprensa, das associações, das escolas e dos próprios intercâmbios entre os dois países. Sobre os primórdios da imigração polonesa, registros de Piton (1971) apontam que os primeiros escritos aconteceram em 1892, com a fundação do Jornal Gazeta Polska w Brazylií. Um jornal que mesmo passando por muitas dificuldades como as constantes mudanças de redatores e correspondentes, seguiu regularmente por quase 50 anos contínuos fazendo publicações, mesmo que nem sempre suficientemente substanciais em termos de conteúdo. A publicação do seu último número foi registrada em 1941. Os principais assuntos tratados diziam respeito às questões sociais, religiosas, políticas, alguns artigos científicos e às vezes algumas sátiras humorísticas. O incentivo à criação de novos jornais veio principalmente por parte da Polônia que visava, sobretudo, fortalecer a disseminação da cultura entre os imigrantes, de uma forma semelhante àquela que ocorria entre os imigrantes italianos e alemães.

\footnotetext{
6 Jornal Polonês no Brasil - Primeiro jornal fundado pelos imigrantes na cidade de Curitiba e de maior abrangência pelo país. Em 1935, eram tirados 3000 exemplares mensais que circulavam entre os estados do Paraná, Santa Catarina, São Paulo, Mato Grosso, Minas Gerais e Rio de Janeiro (PITON, 1971).
} 
Ademais, o jornal era considerado um dos principais materiais didáticos das escolas no Brasil, tendo em vista que era usado como livro de leitura escolar entre os alunos. Entre os adultos, a leitura dos jornais era uma forma de deixá-los conectados com o mundo por meio daquilo que tinham em comum, ou seja, a cultura derivante das origens polonesas.

Segundo dados de Piton (1971), inúmeros jornais foram organizados no período entreguerras por organizações polonesas com perspectivas e orientações ideológicas diferenciadas. Contudo, em 1935, o jornal polonês Polacy Zagranicą destacou 11 jornais organizados pelos imigrantes e publicados no Brasil, os quais acreditamos serem os mais relevantes para a comunidade polonesa, pois além desses, estudos de Piton (1971) apontam que existiam outros em menor escala.

Tabela 2: Relação dos jornais fundados por imigrantes poloneses no Brasil (1892-1935)

\begin{tabular}{|l|l|l|}
\hline Nome original & Nome traduzido & Sede do Jornal \\
\hline 1. Gazeta Polska w Brazylii & 1. Jornal Polonês no Brasil & 1. Curitiba \\
\hline 2. Lud & 2. O Povo & 2. Curitiba \\
\hline 3. Nasza Praca & 3. Nosso Trabalho & 3. Curitiba \\
\hline 4. Nasza Szkółka & 4. Nossa Escolinha & 4. Curitiba \\
\hline 5. Odrodzenie & 5. Renascimento & 5. Rio Grande do Sul \\
\hline 6. Polska Prawda w Brazylii & 6. Polônia verdadeira no Brasil & 6. Curitiba \\
\hline 7. Świt & 7. O nascer do Sol & 7. Curitiba \\
\hline 8. Przyjaciel Rodziny & 8. Amigo da família & 8. Curitiba \\
\hline 9. Saramata & 9. Sármata & Organização de Estudantes do Paraná \\
\hline 10. Gazeta Szkolna & 10. Jornal Escolar & ------- \\
\hline 11. Brasil - Polônia & 11. Brasil - Polônia & 11. Rio de Janeiro \\
\hline
\end{tabular}

Fonte: Fonte: ŻABKO. P. B; Rozwój i znaczenie pracy polskiej w Brazylji. Polacy Zagranicą, Warszawa, Rok 6, n. 9, IX. 1935, S.12.

Para o autor da reportagem, Żabko-Potopowicz (1935), se comparado aos Estados Unidos, os imigrantes no Brasil tinham pouca infraestrutura e equipe técnica para a edição e publicação de notícias em jornais. Além disso, nem todos os jornais tinham muita tiragem porque era difícil encaminhar os exemplares para diferentes regiões do Brasil, tendo em vista que muitas vezes atrasavam ou até se perdiam pelo caminho, não chegando até as colônias mais longínquas. Somado às dificuldades de propagação das 
notícias, nem todos os colonos sabiam ler e muitos deles não tinham tempo, pois o trabalho na lavoura era sua maior prioridade.

Sobre a escolarização na sociedade rural, o escritor e dramaturgo polonês, Jerzy Kossowski, ao decidir ir morar com sua esposa no Brasil, e como fruto das suas observações a respeito da realidade social brasileira, publicou em agosto de 1937, no jornal Polacy Zagranica, um artigo sobre os jovens brasileiros. No artigo, Kossowski asseverou sobre a falta de escolas adequadas aos jovens, destacando que o Governo brasileiro não mantinha ainda o compromisso com a educação dos jovens se comparado à Polônia (KOSSOWSKI, 1937). Acrescentou por fim, que o número de escolas havia se expandido no Brasil quando comparado aos anos de 1920. Todavia, muitas escolas sofriam com a falta de professores, de dinheiro, de material escolar e até pela falta de materiais e terrenos para a construção e ampliação dos prédios escolares. Somada a essas dificuldades, muitos jovens precisavam andar horas a pé até chegarem à escola e a evasão dos estudantes era grande, provocada principalmente pelas intempéries da natureza, pelas sazonalidades do plantio e colheita, mas também por dificuldades distintas que se deviam a pouca infraestrutura das colônias polonesas no Brasil. Sobre essas questões levantadas por Kossowski (1937), elas também foram temas recorrentes das publicações de Carneiro Leão, o qual elevou a ideia de promover uma "educação popular" para o homem do campo, com o intuito de melhorar sua situação socioeconômica:

O Brazil precisa se convencer de que não são conchavos políticos nem regimes, não será o parlamentarismo nem a revisão constitucional nem nada disto que lhe dará a segurança futura, mas o trabalho, a iniciativa, a energia applicada e perseverante. [...] Que se convençam todos de que para a grandeza de um povo a educação paira acima de partidos, de políticos e até de instituições. (CARNEIRO LEÃO, 1917, p. 34)

Percebemos aqui que a educação do povo era tema constante tanto do lado polonês quanto do lado brasileiro. Kossowski (1937) sinalizou que as associações de imigrantes haviam buscado fazer parcerias com a Igreja Católica e com o Governo nacional para que as escolas particulares fossem subsidiadas pelo poder público. Por outro lado, ressalta que nas escolas onde se contava com a participação do poder 
público, o ensino de história e geografia do Brasil era obrigatório na língua portuguesa, e assim, surgia uma outra dificuldade relacionada ao atendimento escolar, quando nem todos os professores falavam português.

Com alguns dados estatísticos, Kossowski (1937) destacou que em 1923, 6.000 crianças e jovens de 6 a 20 anos estavam matriculados em 144 escolas polonesas nos cursos primários, atendidos por 153 professores. E acrescentou que apenas 10\% dos filhos dos imigrantes estavam matriculados em escolas polonesas, os demais frequentavam escolas brasileiras ou alemãs, principalmente nos estados de Santa Catarina e no Rio Grande do Sul. Em relação aos níveis de ensino mais elevado, destacou que as faculdades, com o passar dos anos, começaram a formar os primeiros grupos de jovens urbanos e as primeiras universidades estavam se consolidando. Kossowski (1937), também mencionou que durante uma conversa com o Dr. Amaral, Reitor da Universidade de Curitiba, descobriu que existiam alguns professores poloneses, os quais foram qualificados pelo Reitor como bastante ágeis e capacitados.

Ainda em relação à escolarização dos jovens, o jornalista destacou que mesmo que estivessem começando a se consolidar as primeiras escolas secundárias, profissionalizantes, de ensino técnico e as universidades, diferente da Polônia, nem todos os filhos dos imigrantes poloneses prosseguiam nos estudos. Uma parcela dos jovens precisava trabalhar, ajudar suas famílias nas colônias e aqueles que residiam nas cidades como em Curitiba, por exemplo, acabavam muitas vezes se interessando por esportes e não priorizavam a formação escolar. Por fim, reforçou que se comparar a realidade dos jovens residentes no Brasil com os jovens que viviam na Polônia, o acesso à escola era muito mais difícil. Por outro lado, asseverou que aqueles jovens que adquiriram algum diploma escolar conseguiam facilmente um trabalho de destaque na sociedade brasileira e nesse ponto, o país era cheio de oportunidades aos jovens recém-formados.

Os imigrantes que viviam nas colônias eram, em sua maioria, trabalhadores com pouca ou nenhuma escolaridade. Segundo dados estatísticos apresentados pelo Polacy Zagranica, em junho de 1937, na capital brasileira, Rio de Janeiro, viviam apenas 500 famílias vindas da Polônia (DOBROMILSKI, 1937). Isso significa que a grande maioria dos imigrantes poloneses estava se instalando em pequenos munícipios da região Sul, 
frequentemente nas colônias mais distantes dos maiores centros urbanos, com exceção da cidade de Curitiba.

Conforme novas famílias iam chegando, restavam-lhe as terras de mais difícil acesso e, portanto, precisavam se deslocar por mais tempo do litoral para lugares distantes das escolas e igrejas, além de estarem longe do apoio da Associação de agricultores poloneses que mantinham sua sede em Curitiba. Kossowski (1937) se mostrou bastante preocupado, especialmente com esses jovens que viviam no campo desprovidos do acesso aos bens materiais e culturais. E como forma de amenizar essa insuficiência, o jornalista polonês sugestionou o incentivo à vinda de professores poloneses que pudessem ensinar os filhos dos imigrantes, tendo em vista que a Polônia já possuía um bom quadro de professores formados. Entretanto, tal proposta apresentava outras barreiras de efetivação porque o Brasil não tinha dinheiro para incentivar a vinda desses profissionais, que também não conheciam a língua oficial do Brasil, tendo em vista que o Governo brasileiro vinha exigindo cada vez mais que as aulas nas escolas fossem ministradas em português.

\section{A concessão de bolsas de estudos para filhos de imigrantes poloneses na escola agrícola de Blichu}

Em janeiro de 1937, três estudantes brasileiros, encaminhados pela Associação de agricultores poloneses no Brasil, foram matriculados no curso agrícola de Blichu na Polônia. Cada estudante foi contemplado com uma bolsa de estudos para o curso agrícola de um ano, destinado aos filhos de camponeses na escola Tadeusz Kościuszki em Blichu/Polônia. Além da bolsa, as demais despesas das viagens e taxas foram pagas e emitidas pelo Consulado polonês no Brasil como consta nos documentos encontrados na pasta “Cursos Agrícolas - Brasil” no arquivo em Varsóvia.

A Escola Tadeusz Kościuszki, também conhecida como Escola Agrícola de Blichu, situada no município de Łowicz, foi fundada em 1925 e atendia rapazes, filhos de camponeses em sistema de internato durante um ano letivo. Durante o período da II Guerra, a escola foi ocupada pelos soldados nazistas e as residências dos professores serviram de base para os oficiais do exército. Toda a documentação escolar e a biblioteca 
foram destruídos. Entretanto, encontramos no Arquivo de Atas Novas em Varsóvia, alguns documentos oficiais que tratam da oficialização e do acompanhamento de jovens brasileiros que embarcaram para a Polônia nos anos letivos de 1937 e 1938. No total, foram seis jovens: três durante o ano de 1937 e mais três durante o ano de 1938, entre os meses de janeiro e dezembro.

A escola de Blichu continua sendo até hoje uma instituição polonesa, ligada à formação e preparação técnica de estudantes que queiram atuar nas áreas agrícolas. Em 1944, dois meses depois da desocupação dos nazistas, a escola começou a ser reconstruída por um esforço conjunto de pais e professores e, em 3 de março de 1945, voltou a funcionar. Passados mais dois meses, em maio de 1945, a escola adotou o sistema de coeducação 7 e passou a receber também as filhas de camponeses. Houve também uma expansão para novos e diferentes cursos como música, canto e dança. Em 1948, o curso agrícola foi transformado em curso secundário de quatro anos e, em 1951, foi reeditado para três anos quando passou a ofertar o ensino secundário aliado ao ensino técnico agrícola e as formações culturais.

Segundo os dados atuais da escola, foram formados 500 estudantes antes da II Guerra e 5.500 após a reconstrução da escola, em 1945. Atualmente, a escola continua sendo pública e oferece cursos de mecanização agrícola, agronegócio, nutrição, logística, contabilidade, informática, energia renovável e segurança do trabalho. Em parceria com o Departamento de ciências naturais da Universidade de Varsóvia, sua sede serve como campo de experimentação e estágio para os cursos de agronomia e biologia.

Diante do modelo de curso agrícola destinado aos jovens filhos de camponeses na Polônia, na década de 1930, encontramos modelo semelhante de escola no Brasil nos escritos de Carneiro Leão, quando traçou um diagnóstico da educação rural e apresentou os quadros e currículos das principais escolas do país. Carneiro Leão citou a Escola Agrícola Luiz de Queiroz, em Piracicaba, no estado de São Paulo, como bastante inovadora para a época, sobretudo na década de 1930, principalmente pela sua infraestrutura e por isso, almejada por muitos jovens estudantes. Mesmo assim, a escola

\footnotetext{
7 Vale lembrar que no Ocidente, a coeducação (escolas voltadas para meninos e meninas) ganhou visibilidade, especialmente entre as décadas de 1930/1940, incentivada em grande medida pelos precursores da Escola Nova (AZEVEDO, 2010).
} 
em 1938, ainda não tinha um currículo de educação agrícola vocacional, ou seja, uma educação que despertasse nos filhos de agricultores a missão de continuarem sendo agricultores. Portanto, essa foi uma das questões discutidas em 1937, em São Paulo, durante o Primeiro Congresso Brasileiro de Ensino Rural:

1). Qual a Escola que melhor atende as necessidades sociais e econômicas do país? 2). O que a educação poderá fazer para preparar o homem do campo para uma vida de trabalho racional e produtivo? 3). Como evitar o êxodo dos campos e qual o elemento que mais agrava este problema? 4). Como os professores podem encaminhar soluções para o Brasil? 5). Como a educação e a higiene podem contribuir para valorizar 0 trabalhador nacional? 6). Basta o braço nacional ou que outro elemento estrangeiro convém ao Brasil? 7). É ou não a escola o único elemento capaz de processar a assimilação dos imigrantes? 8). O que é aconselhável, crescer lentamente com elementos nossos ou sujeitar o país ao perigo da formação de quistos raciais com elementos pouco assimiláveis? 9). Será aconselhável o deslocamento de filhos do norte ou do sul para outras regiões do país ainda despovoadas? (CARNEIRO LEÃO, 1939, p. 295-296)

Sobre as questões levantadas durante o I Congresso de ensino rural, algumas ações pontuais já vinham sendo desenvolvidas, quando o jornal polonês Polacy Zagranica, publicou, em janeiro de 1938, que as inovações agrícolas no Brasil vinham também beneficiando as colônias polonesas, e como exemplo citou um encontro dos colonos com técnicos agrícolas, às margens do Rio Ivaí no estado do Paraná ${ }^{8}$. Meses depois, em outra passagem, o jornal citou a questão da pecuária e registrou por meio de fotografias, bovinos da Polônia que estavam sendo transportados para procriarem nos pampas brasileiros, mais precisamente em Affonso Penna, no Paraná9. Mais adiante, outra nota publicada no mês de maio anunciou que graças à Associação de poloneses no Brasil, a Polônia conseguiu negociar com o estado do Paraná a venda de vinte toneladas de cereais ${ }^{10}$.

Em suma, durante a leitura dos jornais, podemos perceber que em relação aos temas vinculados ao Brasil e, principalmente às notas que tratavam da economia desse país, mormente estavam voltadas à produção e o cultivo da terra, isto é, eram notas e

\footnotetext{
${ }^{8}$ WARSZTATY przemysłowe dla polskich osadników w Brazylii. Polacy Zagranicą, Warszawa, Rok 9, n. 1, s. 14, I. 1938.

9 POLSKIE bydło na pampasach. Polacy Zagranica, Warszawa, Rok 9, n. 4, s. 57, IV. 1938.

${ }^{10}$ DZIĘKI polskiemu imigrantom, Brayzlia kupuje zboże s Polski. Polacy Zagranica, Varsóvia, ano 8, n. 5, p. 49, maio 1937.
} 
artigos que tratavam diretamente das riquezas naturais desse país. Temas como a organização das propriedades, o trabalho na lavoura, as igrejas e escolas nas colônias, e por fim, as relações comerciais que começavam a se estabelecer nos últimos anos entre os dois países. São observações realizadas a partir dos escritos de Carneiro Leão e que coadunam com aquilo que o educador brasileiro tanto enfatizou ao afirmar inúmeras vezes que este era um país fundamentalmente agrícola.

\section{O processo de recrutamento e a formação dos jovens rapazes no curso agrícola}

Em 9 de agosto de 1937, o Ministério das Relações Internacionais polonesas encaminhou um ofício à Associação de agricultores poloneses em Curitiba anunciando novas bolsas de estudos para jovens agricultores, filhos de imigrantes, para o que seria o próximo ano. Cabe aqui destacar que no ano letivo em questão, já estavam matriculados no curso agrícola três jovens vindos do Brasil: Jósef Moskarz, Karol Mikowski e Kazimierz Leonard Stasiak. Eram jovens matriculados em uma escola vocacional para a agricultura ${ }^{11}$.

Na época, conforme consta nos documentos mencionados, a escola tinha como missão trazer inovações técnicas para que os futuros agricultores pudessem se capacitar nos processos de produção para atuarem nas suas colônias de terra. Além da educação cívica e profissional, os jovens formados estariam capacitados para a gestão financeira de suas propriedades.

O ano letivo iniciou em 15 de janeiro e terminou em 15 de dezembro. O currículo do curso contava com as seguintes disciplinas: religião, língua e literatura polonesa, matemática, história da Polônia, geografia, ciências naturais, mecanização das lavouras, criação de animais, pecuária, veterinária, apicultura, jardinagem, organização e administração de negócios e associações cooperativas. Também eram realizadas atividades práticas no terreno da escola que contava com 60 morgen, ou aproximadamente 15 hectares de terra. A escola também buscava ser autossustentável, isto é, produzir para o consumo dos estudantes e comercializar o excedente.

\footnotetext{
${ }^{11}$ Mais informações podem ser obtidas no Boletim Tak, organizado pela Casa da Cultura Polônia Brasil e apoiado pelo Consulado Geral da República da Polônia em Curitiba. Curso Agrícola para brasileiros na Polônia (1937-1938). Boletim Tak! Agenda Cultural Polônia Brasil. N.12. set/out 2019.
} 
Os estudantes tinham 5 horas de aulas teóricas e, de 4 a 5 horas de aulas práticas por dia. O resto do tempo se destinava às atividades lúdicas, música, ginástica e autoorganização. Eram aceitos pela escola rapazes de 17 a 24 anos de idade e que tenham concluído os quatro anos do ensino primário. Os estudantes ainda deviam pagar 25 PLN por mês, correspondente à moeda polonesa, pela moradia no internato.

Em 14 de dezembro de 1937, o Diretor da escola encaminhou um ofício registrando o encerramento do curso ofertado aos três jovens estudantes vindos do Brasil: Stasiak, Mikołowski e Mośkorz, com as avaliações do desempenho alcançado nas disciplinas cursadas durante o curso.

Figura 2 - Registro do desempenho escolar

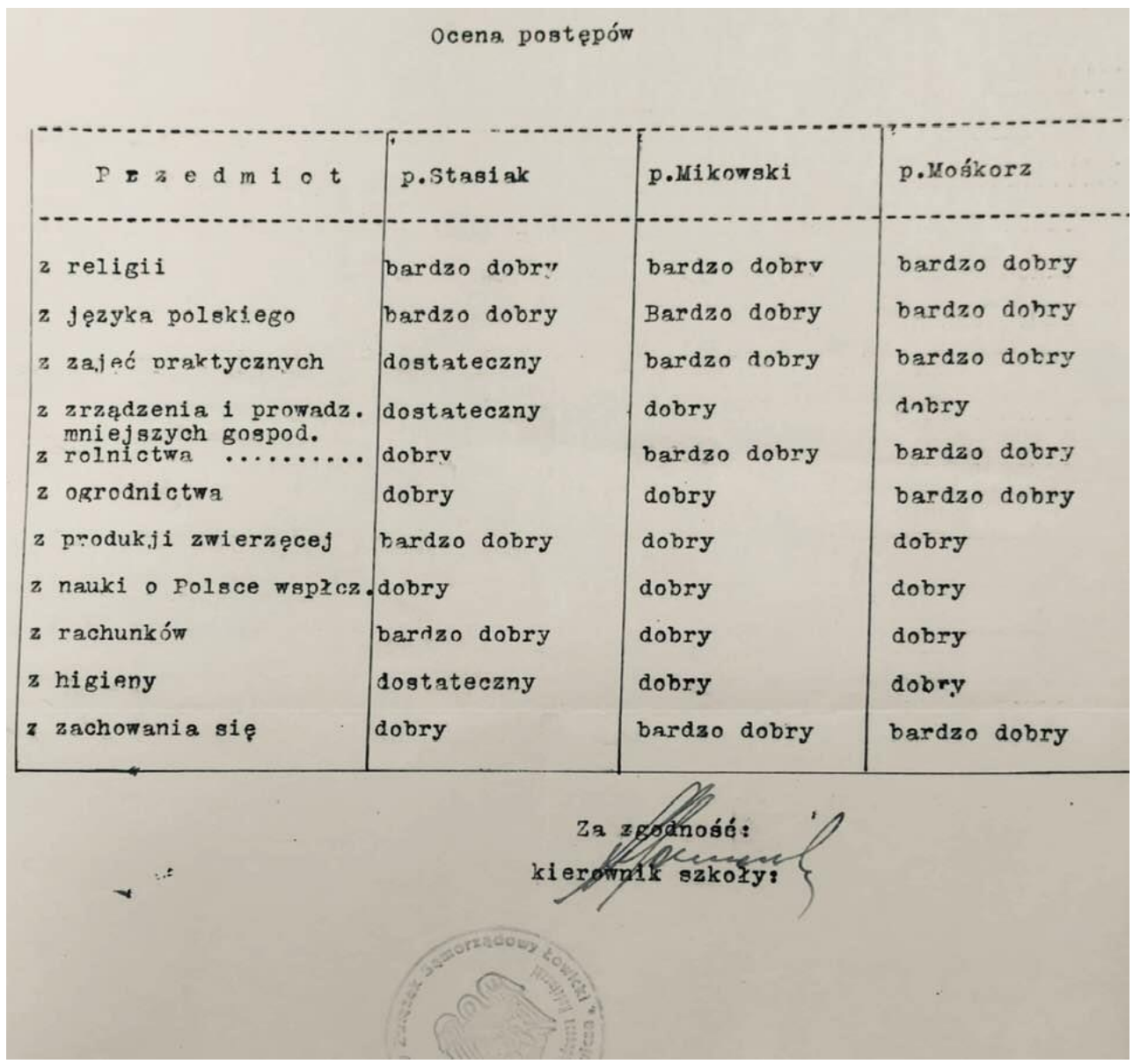

Fonte: KURSY Rolnicze - Brazylia. Ocena postępżow. Archiwum Akt Nowych: Warszawa.1937.s. 13 . 
Tabela 3: Transcrição do desempenho escolar dos estudantes

\begin{tabular}{|l|l|l|l|}
\hline Disciplinas & Stasiak & Mikowski & Móskorz \\
\hline Religião & Muito Bom & Muito Bom & Muito Bom \\
\hline Língua polonesa & Muito Bom & Muito Bom & Muito Bom \\
\hline Atividades práticas & Suficiente & Muito Bom & Muito Bom \\
\hline Gerenciamento e liderança de pequenas economias & Suficiente & Bom & Bom \\
\hline Agricultura & Bom & Muito Bom & Muito Bom \\
\hline Jardinagem & Bom & Bom & Muito Bom \\
\hline Produção animal & Muito Bom & Bom & Bom \\
\hline Ciências Contemporâneas na Polônia & Bom & Bom & Bom \\
\hline Matemática & Muito Bom & Bom & Bom \\
\hline Higiene & Suficiente & Bom & Bom \\
\hline Comportamento & Bom & Muito Bom & Muito Bom \\
\hline
\end{tabular}

Tradução do Autor. (2019).

Podemos perceber pelo desempenho na avaliação dos estudantes que todos apresentaram um desempenho satisfatório, o que nos leva a pensar que não encontraram grandes dificuldades ao realizar um curso agrícola em um país de língua polonesa. Contudo, podemos melhor verificar isso quando um artigo foi publicado pelo jornal Polacy Zagranicą, em junho de 1938, escrito por um dos estudantes - Karol Mikowski que estava matriculado no curso durante o ano letivo de 1937 (MIKOWSKI, 1938).

Figura 3 - MIKOWSKI, Karol. Rolnicza młodzież polska z Brazylii na kursach w Polsce

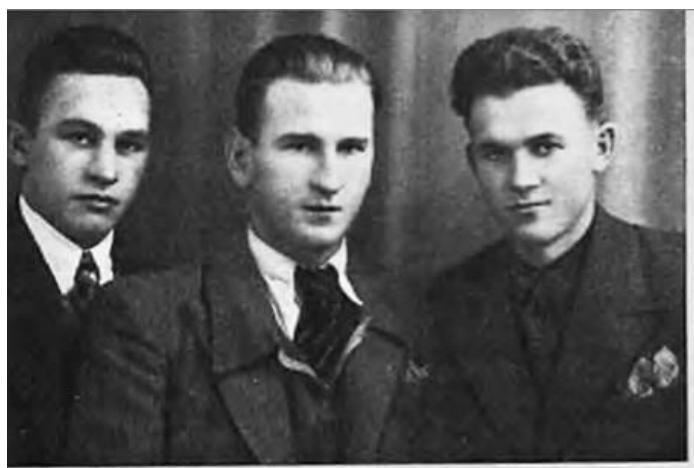

\section{ROLNICZA MKODZIEŻ POLSKA Z BRAZYLII NA KURSACH W POLSCE}

Moćkorz, Stasiak, K. Mikowski.

Polacy Zagranica, Warszawa, Rok. 9, n. 6, VI. 1938, s.16.

Mikowski inicia o artigo agradecendo à Polônia pelo ato louvável de receber jovens estudantes de uma terra tão distante quanto é o Brasil. Em seguida, relatou que 
junto com os demais colegas, a vinda para um lugar tão longínquo significou a consolidação de um sonho plantado durante as histórias que ouviam em suas famílias e aquilo que encontravam escrito nos jornais durante os tempos de escola. O estudante descreve que escolheu o curso para poder olhar para as propriedades rurais com mais responsabilidade e liderança, tendo em vista que muitas vezes, a comercialização daquilo que era produzido nas colônias ocorria somente pela troca entre os vizinhos, sem necessariamente, obter um lucro financeiro com aquilo que produziam nas colônias. $E$ assim, ressalta que os conhecimentos aprendidos durante o curso foram importantes para ter um olhar qualificado sobre as propriedades rurais. Por fim, acrescenta que, juntamente com seus dois colegas, essa qualificação obtida durante um curso agrícola no país de seus parentais, tornou-os pessoas mais distintas e respeitadas nas colônias em que viviam no momento.

Em seguida, complementou que muitas vezes ouviu histórias de camponeses poloneses no Brasil que o faziam pensar bastante, como aquelas que se devem a pouca habilidade de administrar uma propriedade rural e por isso, os colonos-imigrantes vendiam suas colônias de terras para os imigrantes alemães ou japoneses, e continuavam a fumar o seu cigarro sem saber o que fazer, ou então, passavam a ser trabalhadores empregados dos alemães. Para o jovem Mikowski, isso ocorria porque diferente dos alemães e japoneses, que tiveram mais informações sobre gestão das propriedades rurais na escola, os imigrantes poloneses ainda careciam dessa formação escolar e, por isso, continuavam trabalhando da mesma forma que seus avós e bisavós. E assim, exaltou a atuação da Associação de agricultores poloneses no Brasil que estaria possibilitando essa oportunidade aos jovens agricultores.

O jovem relatou como bastante positiva essa experiência que reverberava em resultados produtivos após o retorno ao Brasil. Além do conhecimento aprendido na escola, também destacou o contato com a língua, com as histórias da sua família e com o vasto campo literário com os quais jamais teria contato em seu país. Comentou também sobre uma viagem de campo para Liskowa, que fica a cerca de uma hora de Blichu, para visitar uma plantação de frutas resultando num dia memorável pelas amizades estabelecidas durante essa viagem. 
O jovem ainda complementou que durante o ano letivo realizaram diversos trabalhos sociais e de gestão das propriedades. Também foram oportunizados de conhecer a pátria dos seus ancestrais, a vida do povo e a bonita forma de falar a língua polonesa. O tempo passou rápido, mas foram construídas muitas amizades e o retorno não foi fácil. Por outro lado, citou que voltaram mais alegres porque podiam ensinar aos demais colonos-imigrantes o que aprenderam naquele curso que durou onze meses.

Por fim, salientou a hospitalidade com os irmãos poloneses e os tempos inesquecíveis que passaram juntos. Finalizou o artigo dizendo que jamais esqueceria o tempo que passaram juntos; rememorou, para continuarem sendo lembrados pelos colegas da Polônia, e agradeceu mais uma vez à Associação de poloneses no Brasil pela oportunidade que tiveram de poder conhecer e amar esse país mais de perto.

Como já mencionamos, em agosto de 1937, a Associação de agricultores poloneses no Brasil, recebeu a confirmação da oferta de novas bolsas de estudo para filhos de camponeses para o ano de 1938. Um segundo ofício foi encaminhado em outubro de 1937, solicitando que os candidatos não fossem professores e sim agricultores, e também advertia que deveriam trazer roupas e calçados quentes, adequados para as atividades práticas no campo, e durante a estada de um ano letivo não teriam tempo para férias. Ao final do documento, avisa que após a conclusão do curso pelos estudantes matriculados no corrente ano: Stasiak, Mikowski e Móskorz, as notas das disciplinas seriam encaminhadas para a associação, as quais foram aqui apresentadas.

Diante do comunicado recebido, em 18 de outubro de 1937, a Associação de agricultores poloneses encaminhou três pastas com a inscrição dos novos candidatos para 1938, com o perfil de cada um:

1) Mieczysław Wierzyński - 21 anos, nascido no Brasil, na Colônia Affonso Penna próximo a Curitiba, concluiu o ensino primário. Cumpriu o serviço militar e possui título de eleitor. É o filho do presidente da Associação de agricultores poloneses no Brasil. Trabalhou inicialmente numa floricultura por um ano e meio, e atualmente auxilia o pai como jardineiro na colônia em Morretes, a qual possui 80 hectares de terra onde se produz frutas e verduras. 
2) Jan Ambroziak - 23 anos, nascido na Colônia Thomas Coelho, próximo a Curitiba. Estudava na Escola das Irmãs, mas não concluiu a escola por causa da morte do seu pai. Inicialmente trabalhou como ajudante da mãe em uma colônia de 24 hectares de terra. O jovem foi dispensado do serviço militar e possui título de eleitor. Ultimamente trabalhou como ajudante do seu tio Wojciech Serafin, proprietário de uma fazenda em Rio Azul próximo de Mallet.

3) Jan Śikorski - 21 anos, nasceu na Colônia Cruz Machado, é cidadão brasileiro, concluiu os estudos no Colégio Nicolau Copérnico em Mallet, também já encerrou o serviço militar e possui título de eleitor. Concluiu a escola e agora estuda em casa com ajuda de uma professora particular. A Colônia Pinhão em Cruz Machado, onde vivem, possui 40 hectares de terra.

Ao final do documento, ainda encontramos uma observação destacando que o filho do secretário da Associação de agricultores poloneses ainda não havia concluído o serviço militar, portanto, sua candidatura não poderia ser encaminhada junto com os demais jovens apresentados. O ofício complementa que os estudantes deveriam embarcar em 22 de novembro de 1937, pela linha Santos-Gdynia.

Diante do perfil dos candidatos apresentado, gostaríamos de levantar algumas observações e destacar que todos apresentavam uma ligação com a terra, seja pelo número de hectares das propriedades rurais ou pela atuação profissional de cada um deles, além de serem cidadãos brasileiros que já cumpriram ou foram dispensados do serviço militar. Eram votantes e não exerciam nenhum tipo de docência, atendendo ao que foi solicitado pelo Ministério das Relações Internacionais da Polônia durante o encaminhamento do primeiro ofício de recrutamento de novos estudantes para o ano de 1938. Enfim, se apresentavam como jovens potenciais para o progresso da agricultura.

Ainda sobre o encaminhamento dos novos estudantes, uma semana depois, em 30 de novembro de 1937, um ofício foi enviado ao Ministério das Relações Internacionais comunicando que o candidato Jan Śikorski não embarcou porque não conseguiu chegar em Curitiba no tempo previsto, solicitando, assim, um novo bilhete para o estudante que deveria embarcar no próximo navio Amerika - Gdynia. 


\section{Os jovens e a educação no contexto da imigração}

A atual economia brasileira reverbera um passado de vocação agrícola, como bem sinalizou Carneiro Leão: "O Brasil é um dos países que se destaca mundialmente pela produção de commodities e, portanto, tem uma forte relação com a produção que vem da terra" (NAWROSKI, 2019, p. 334). Sendo assim, podemos compreender a presença massiva de agricultores que deixavam a Polônia para se instalar no Brasil durante os anos da "febre brasileira". Para Carneiro Leão, ao desembarcar nas novas terras, os imigrantes precisavam se adaptar ao país que os atendia à medida que os imigrantes estivessem receptivos à assimilação da nova cultura. Portanto, ao apropriar-se do conceito de "ecologia humana12", o educador destacou que "o homem capaz de melhor dominar o ambiente é aquele que consegue um equilíbrio ecológico mais perfeito" (CARNEIRO LEÃO, 1953, p. 172), e assim não corre o risco de abandonar a terra que cultiva.

Prosseguindo com a política de assimilação cultural, Czesław Kulikowski, cônsul polonês em Curitiba, durante os anos de 1934 e 1935, publicou em junho de 1937, um artigo sobre os rastros poloneses no Brasil, no jornal Polacy Zagranica, quando inferiu que cada vez mais, os imigrantes poloneses assimilam as características do povo brasileiro (KULIKOWSKI, 1937). Como exemplo, citou o uso de botas até o joelho para andar a cavalo. Kulikowski (1937) destacou que a assimilação também ocorria por uma questão de sobrevivência dos imigrantes, tendo em vista que o clima e as condições das terras são diferentes da Polônia. Dessa forma, imigrantes e descendentes começavam a se identificar como gaúchos ou tropeiros. Entretanto, cita a igreja e a escola como os lugares em que a assimilação da cultura brasileira ficava mais evidente. Na escola, cada vez mais os imigrantes são influenciados pela língua local - o português, deixando para os espaços do ambiente familiar uma língua polonesa vulgar que quase não se encontra mais na Polônia.

O ex-cônsul Kulikowski (1937) também comentou a respeito do gosto que os imigrantes tinham pela terra, assegurando que era perfeitamente compreensível que as antigas preferências dos imigrantes pelo campo continuassem sendo desenvolvidas no

\footnotetext{
${ }^{12}$ Conceito desenvolvido por Robert Ezra Park da Escola de Chicago, utilizado por Carneiro Leão para tratar de uma sociologia e de uma psicologia experimental que fosse capaz de adaptar o homem ao campo (CARNEIRO LEÃO, 1953).
} 
Brasil, tendo em vista a diversidade socioambiental desse lugar. Destacou ainda que os imigrantes poloneses construíam suas casas de madeira ao invés do barro, levando em conta o fácil acesso à madeira, principalmente nos estados do Paraná e Santa Catarina. Entretanto, as paredes eram finas e não tinham a mesma espessura das casas construídas nas aldeias polonesas. Por fim, salientou que, em relação aos rastros arquitetônicos dos imigrantes, o prédio do Colégio Nicolau Copérnico em Mallet, no Paraná, era o que mais se assemelhava com a arquitetura encontrada na Polônia.

Em relação aos atos em prol da nacionalização do ensino, levantados em 1918, e intensificado nos anos seguintes, o jornal Polacy Zagranica (1938) destacou que durante a década de 1930, eram cada vez mais preocupantes as ações que vinham ocorrendo no Brasil, como aquelas que forçaram, pela imposição da própria sociedade, que não se deveria falar a língua materna nos espaços em que houvesse presença de brasileiros que não compreendessem o idioma. Em relação ao movimento de nacionalização do ensino, a preocupação com a língua materna dos imigrantes na região Sul, apontada por Carneiro Leão, era bastante evidente; se por parte dos poloneses havia um esforço de manutenção da cultura de origem, por parte do Estado brasileiro havia um movimento forçado de assimilação da cultura local. Portanto, as escolas deveriam "compensar o conteúdo 'patriótico' sentimental e idealista do nacionalismo com um conteúdo fundado mais no 'conhecimento' da terra e da gente brasileira” (NAGLE, 1974, p. 272), e obrigatoriamente na língua nacional.

Sobre o movimento de nacionalização do ensino, o Jornal Polacy Zagranica, registrou um encontro de Júlio Grabowski, político de Araucária, com Francisco Campos, em 1937, para tratar especialmente da situação dos imigrantes poloneses. O jornal relata que segundo Campos, a nacionalização da educação não impedira os imigrantes poloneses de sentirem carinho e afeto pela sua primeira pátria ${ }^{13}$. Mas, em seguida endureceu nas colocações e salientou que os imigrantes precisavam se sentir brasileiros para terem seus direitos de saúde e educação garantidos. E finalizou, dizendo que o

\footnotetext{
${ }^{13}$ POLACY w Brazylii przeżywaja trudne czasy. Polacy Zagranica, Varsóvia, ano 3, n. 8, p. 22, ago. 1937.
} 
Governo brasileiro não queria que o país fosse um lugar de passagem para os imigrantes, mas de fixação, onde pudessem viver felizes com suas famílias.

Em relação às medidas, na forma de decretos, que o Governo brasileiro vinha tomando, a matéria do jornal mencionada (POLACY W BRAZYLII PRZEŻYWAJA TRUDNE CZASY, 1938), que tratou dos tempos difíceis que os emigrados vinham passando no Brasil, apresentou detalhes dos decretos do Governo que estavam mudando a vida de aproximadamente 300.000 polono-brasileiros. Segundo a reportagem, por conta de um processo forçado de nacionalização que vinha sendo implantado há algum tempo e culminou no dia 4 de maio, com o Decreto-Lei n 406, também conhecido como "Lei da Nacionalização" cujos resultados ainda não se poderia prever, mas já se poderia esperar pelo pior, ou seja, um rompimento com todas as associações de imigrantes no Brasil.

A reportagem do jornal, ainda destacou que no mês janeiro de 1938, foram realizadas atividades de fiscalização por órgãos do Governo sobre as atividades que vinham sendo realizadas pelos grupos de apoio aos imigrantes. Mais tarde, em março do mesmo ano, foram fechados, o escritório sede da União Central dos Poloneses e a Associação de Professores das Escolas Polonesas. E por fim, como última medida, em 3 de maio de 1938, a Sociedade de Educação Física - Junak, criada em 1923, para formação física, civil e cultural dos jovens descendentes de imigrantes, que foi substituída por Sociedade de Educação Física - Juventus. Para o historiador polonês Wywiał (2012), que tratou em um texto sobre a intervenção militar brasileira durante a "Era Vargas", a vida cultural dos imigrantes poloneses, altiva desde a construção da primeira escola étnica, em 1876, pelo pedagogo Hieronim Durski nas proximidades de Curitiba, e a consolidação do Junak, em 1923, tiveram seu fim em 1938. De acordo com outra reportagem publicada pelo Polacy Zagranicą, em junho de $1937^{14}$, o Junak participou ativamente na inauguração do Colégio polonês Władysław Reymont em Guarani das Missões, no estado do Rio Grande do Sul, inaugurado no início do ano letivo de 1937. Mas, segundo Wywiał (2012), por ordem do Governo nacional, teve que encerrar suas atividades em 03 de maio de 1938, um dia antes do Decreto-Lei da Nacionalização.

\footnotetext{
${ }^{14}$ OTWARCIE polskiej sykoły w Guarani. Polacy Zagranicą, Warszawa, Rok 8, n. 5, s. 49, V. 1937.
} 
Importante ainda destacar que no mesmo exemplar do mês de junho de 1938, em que o jornal Polacy Zagranica, publicou uma nota com procedimentos de condolências sobre o fechamento das principais instituições mantenedoras da cultura polonesa no Brasil, algumas páginas mais adiante, também estava publicado o relato do jovem Karol Mikowski, estudante da escola agrícola, em 1937, o qual enfatizamos neste trabalho. Enfim, o ano de 1938 foi marcado pelo fim das relações Brasil-Polônia no que toca a participação do Estado polonês na educação dos imigrantes poloneses, filhos de camponeses no Brasil, mas também marcou o fim de um apoio mais próximo que existia em relação à manutenção da cultura, da língua e das tradições polonesas como tão bem apresentou o estudante Mikowski (1938).

\section{Considerações finais}

Finalizamos o trabalho ressaltando que o processo de nacionalização da educação no Brasil, em 1938, perdurou por mais de vinte anos. Entretanto, a pesquisa se ateve somente em analisar o período iniciado nos idos de 1917/1918, quando Carneiro Leão protagonizou que o Brasil é uma país essencialmente agrícola e, portanto, precisa de uma educação popular para o povo, entendida mais tarde nas palavras do educador como uma educação primordialmente rural.

Sob a enunciação de uma educação rural, verificamos nas relações estabelecidas entre Brasil e Polônia, no que tange à educação dos imigrantes trabalhadores rurais que chegavam ao Brasil, um esforço por parte de alguns educadores, como Carneiro Leão, de elevar uma pedagogia que despertasse o "amor pela terra" por meio de um sentimento de afeição pela terra que nos acolhe e, portanto, deveria ocorrer pela assimilação dos aspectos locais. O educador brasileiro revisitado buscou no conceito de "ecologia humana", estratégias e sequências de ajustamento do homem ao meio rural. Sendo assim, a escola teve papel central nesse processo de adaptação quando foi orientada a criar cursos específicos para a formação de professores, bem como currículos adequados à vida rural, cuja proposta era de uma educação vocacional para que os filhos de camponeses permanecessem no campo, ou seja, uma pedagogia não só de assimilação, mas, de fixação do homem no campo. 
Para Carneiro Leão (1939), cultivar a terra com amor, era mais do que ser apenas um trabalhador, produtor das riquezas do país, todavia, por meio de um processo forçoso era preciso sentir-se sujeito integrante e orgulhoso dessa terra. Assim, esquecer a língua mãe ou, como o próprio Carneiro Leão destacou, deixar a língua apodrecer, ao ser forçado a aprender a língua nacional foi um processo dispendioso, mas necessário segundo o educador brasileiro, para que o país realmente se tornasse uma nação sem anseios de pangermanismo como mencionou quando tratou dos diferentes grupos étnicos na região Sul.

Ao analisar as reportagens do Jornal Polacy Zagranica, juntamente com os documentos encontrados no arquivo mencionado, percebemos que a vocação agrícola do Brasil não foi um tema exclusivamente anunciado por Carneiro Leão, mas o educador realizou um trabalho fundante de porta-voz dessa ideia. Constatamos, ainda, durante as pesquisas, que as relações estabelecidas entre Brasil e Polônia se davam em grande medida por um interesse também econômico em relação à produção da terra. Isso fica explícito quando, grande parte das reportagens publicadas por um jornal que tratava da diáspora polonesa nos mais diversos países, apresentava, em sua maioria, dados e temas do Brasil relacionados às questões rurais deste país; outro fato era a oferta de bolsas de estudos para um curso agrícola; e por fim, o perfil dos imigrante poloneses que imigram ao Brasil, identificados como jovens camponeses, de preferência com família e crianças pequenas.

\section{Referências}

AZEVEDO, Fernando de [et al.]. Manifesto dos pioneiros da Educação Nova (1932). Recife: Fundação Joaquim Nabuco: Ed. Massangana, 2010.

CARNEIRO LEÃO, Antônio. Fundamentos de sociologia. 2. ed. São Paulo: Melhoramentos, 1953.

CARNEIRO LEÃO, Antônio. A sociedade rural: seus problemas e sua educação. Rio de Janeiro: Editora S.A. A Noite, 1939. 
CARNEIRO LEÃO, Antônio. O Brazil e a educação popular. 2. ed. Rio de Janeiro: Jornal do Commercio, 1918.

CARR, Edward. Que é história? São Paulo: Paz e Terra, 1996.

CHARTIER, Roger; e CAVALLO, Guglielmo. (org.) História da leitura no mundo ocidental 1. São Paulo: Ática, 1998. (Coleção Múltiplas Escritas).

DEWEY, John. Democracy and education: an introduction to the philosophy of education. New York: The Macmillan Company, 1916.

KULA, Marcin. Algumas observações sobre a emigração polonesa para o Brasil. Estudios Latinoamericanos, Varsóvia, n. 3, p. 171-178. 1976.

MAZUREK, Jerzy. A Polônia e seus emigrados na América Latina (até 1939). Goiânia: Editora Espaço Acadêmico, 2016.

NAGLE, Jorge. Educação e sociedade na Primeira República. São Paulo: EPU: Edusp, 1974.

NAWROSKI, Alcione. O amor à terra e a função social da educação rural no Brasil (19101964). Revista del CESLA - International Latin American Studies Review. Universidad de Varsóvia: Varsóvia. v. 23, p. 333-354, 2019.

NAWROSKI, Alcione. História e Sociologia como possibilidades de conhecimento. In: MATOS, José Claudio Morelli; BRITO, Evandro Moreira de (org.). Leitura e escrita na construção do conhecimento. São José: Centro universitário de São José, 2015.

PITON, Jan. Periódicos de Língua Polonesa no Brasil. In: Anais da Comunidade BrasileiroPolonesa Volume III. Curitiba: [s.n.], 1971.

TRINDADE, Rhuan Targino Zaleski. A II República da Polônia e os imigrantes poloneses no Brasil meridional (1918-1939). Revista História Helikon, Curitiba, v. 3, n. 6, p. 126-142, 2016.

WYWIAt. Przemysław. Towarzystwo Wychowania Fizycznego 'Junak' w Brazylii, 19231938. Przegląd Historyczno-Wojskowy, v. 13. (64), n.1 (239), p. 198-210, 1 sem. 2012. 


\section{Fontes consultadas}

BRAZYLIA. Dekrety i rozporządzenia imigracyjne. Collection: 2/322/0. Ministerstwo Spraw Zagranicznych w Warszawie » Series: units without series » File/unit: 9640. ( AAN Archiwum Akt Nowych). 1937-1939.

BRAZYLIA - Echa Pierwszego Zjazdu Polaków z Zagranicy. Polacy Zagranicą, Warszawa. Nr. 1, s. 22 - 23, I. 1930.

BRAZYLIA. Powstanie Centralnego Związku Polaków. Polacy Zagranicą, Warszawa, Nr. 4, S. 116 - 117. IV.1930

DAR Świat. Zw. dla rolników polskich w Brazyli. Polacy Zagranicą, Warszawa, Rok 9, n. 5, S. 55, VI. 1938.

DOBROMILSKI W ł. —- Z życia kolonii polskiej w Rio de Janeiro. Polacy Zagranicą, Warszawa, Rok. 8, n. 6, s. 12, VI. 1937.

DZIĘKI polskiemu imigrantom, Brayzlia kupuje zboże s Polski. Polacy Zagranicą, Varsóvia, ano 8, n. 5, p. 49, maio 1937.

KOSSOWSKI Jerzy — O młodzieży brazylijskiej. Polacy Zagranicą, Warszawa, Rok 3, n.8, s. 12, VIII. 1937.

KULIKOWSKI Czesław dr - O znaki zasięgu polskości w Brazylii. Polacy Zagranicą, Warszawa, Rok. 8, n. 6, p. 15, VI. 1937.

KURSY Rolnicze - Brazylia. Collection: 2/61/0. Światowy Związek Polaków z Zagranicy. Biuro w Warszawie. Series: 5.5. Inne kursy organizowane w kraju i zagranicą. (AAN Archiwum Akt Nowych). 1937.

MIKOWSKI, Karol. Rolnicza młodzież polska z Brazylii na kursach w Polsce. Polacy Zagranicą, Warszawa, Rok 9, n. 6, s.16, VI. 1938.

OTWARCIE polskiej sykoły w Guarani. Polacy Zagranicą, Warszawa, Rok 8, n. 5, s. 49, V. 1937.

POLACY w Brazylii przeżywaja trudne czasy. Polacy Zagranicą, Varsóvia, ano 3, n. 8, p. 22, ago. 1937.

POLSKIE bydło na pampasach. Polacy Zagranicą, Warszawa, Rok 9, n. 4, s. 57, IV. 1938. 
WARSZTATY przemysłowe dla polskich osadników w Brazylii. Polacy Zagranicą, Warszawa, Rok 9, n. 1, s. 14, I. 1938.

ŻABKO-Potopowicz Bolesław — Rozwój i znaczenie pracy polskiej w Brazylji. Polacy Zagranicą, Warszawa, Rok 6, n. 9, s. 11-14, IX. 1935.

Recebido em 31/03/2019 Aprovado em 10/08/2019

Universidade do Estado de Santa Catarina - UDESC Programa de Pós-Graduação em História - PPGH Revista Tempo e Argumento Volume 11 - Número 28 - Ano 2019 tempoeargumento@gmail.com 